\title{
Protein Profile and Simulated Digestive Behavior of Breast Milk from Overweight and Normal Weight Mothers
}

\author{
Silvia Sánchez-Hernández ${ }^{1}$, Laëtitia Théron ${ }^{2}$, Pablo Jiménez-Barrios ${ }^{3}{ }^{\circledR}$, Manuel Olalla-Herrera ${ }^{1,4}{ }^{\circledR}$, \\ Isidra Recio $^{3}$ (D) and Beatriz Miralles ${ }^{3, *}$ (D) \\ 1 Departamento de Nutrición y Bromatología, University of Granada, 18071 Granada, Spain; \\ silsanchez@ugr.es (S.S.-H.); olalla@ugr.es (M.O.-H.) \\ 2 Institut National de Recherche Pour l'Agriculture, l'Alimentation et l'Environnement (INRAE), UR370 \\ Qualité des Produits Animaux, F-63122 Saint Genès-Champanelle, France; laetitia.theron@inrae.fr \\ 3 Instituto de Investigación en Ciencias de la Alimentación, CIAL, (CSIC-UAM), Nicolás Cabrera 9, \\ 28049 Madrid, Spain; pablo.jimenez.barrios@csic.es (P.J.-B.); i.recio@csic.es (I.R.) \\ 4 Instituto de Investigación Biosanitaria ibs. GRANADA, University of Granada, 18071 Granada, Spain \\ * Correspondence: beatriz.miralles@csic.es; Tel.: +34-910017932
}

Citation: Sánchez-Hernández, S.;

Théron, L.; Jiménez-Barrios, P.; Olalla-Herrera, M.; Recio, I.; Miralles, B. Protein Profile and Simulated Digestive Behavior of Breast Milk from Overweight and Normal Weight Mothers. Foods 2021, 10, 887. https:// doi.org/10.3390/foods10040887

Academic Editor: Lovedeep Kaur

Received: 26 March 2021

Accepted: 15 April 2021

Published: 18 April 2021

Publisher's Note: MDPI stays neutral with regard to jurisdictional claims in published maps and institutional affiliations.

Copyright: (c) 2021 by the authors. Licensee MDPI, Basel, Switzerland. This article is an open access article distributed under the terms and conditions of the Creative Commons Attribution (CC BY) license (https:/ / creativecommons.org/licenses/by/ $4.0 /)$.

\begin{abstract}
Human milk proteins have shown to vary in concentration and distribution through lactation. However, while some regulatory components, such as hormones, have shown associations with regard to the mothers' body mass index, there is limited information on the possible influence of this condition on the whole protein distribution. The objective of this study was to evaluate the protein profile of human milk from normal weight and overweight or obese mothers to identify differences in protein expression in colostrum, transitional and mature milk. The mass spectrometry analysis showed the ability to class with a high degree of confidence the lactation state and the milk profile according to the mother's condition. Individual milk samples were subjected to a digestion in vitro model that takes into account the specificities of the gastrointestinal conditions of full-term newborn infants. The digestion products were compared with available data from the digestive contents in newborns. The behavior of the most abundant proteins and the overall peptide generation and survival, showed good correspondence with in vivo data.
\end{abstract}

Keywords: human milk; MALDI mass spectrometry; body mass index; in vitro infant digestion; bioactive proteins

\section{Introduction}

Human milk presents a combination of components ideal for infant nutrition, allowing optimal growth and providing several short and long-term health benefits. While lipids are the largest source of energy in breast milk, contributing $40-55 \%$ of the total energy, proteins from breast milk provide approximately $8 \%$ of the energy required by the infant [1]. However, they constitute an essential fraction from the point of view of biological implications, including antimicrobial and immunomodulatory activities, and stimulating the absorption of nutrients [2]. Hormones (such as insulin or adipokines) are contained within the peptide components and may influence energy intake, weight gain, growth and development of infants directly or indirectly [3].

Milk proteins can be classified into caseins, whey proteins and the milk fat globule membrane (MFGM) fraction. Breast milk composition, and concretely the protein fraction, varies during lactation to adapt to the newborn's protein requirements. The total content of casein, suspended in casein micelles, and whey proteins, soluble, change profoundly over time; whey proteins dominate the profile in the first days of lactation compared to virtually undetectable casein [4]. In mature milk, an estimated average whey/casein ratio of 60:40 has been reported, although quantification with proteomics reveals a median whey/casein ratio even lower, 73:27 [5]. Regarding protein composition, the levels of $\alpha$ lactalbumin $(\alpha-\mathrm{LA})$, lactoferrin and $\beta$-casein decrease throughout lactation while, lysozyme 
concentration increases [6]. Milk composition can also vary with mother's phenotype and health status. Increased levels of glucose and insulin are reported in obese and overweight mothers [7]. Maternal body mass index (BMI) is positively correlated with leptin levels in milk [8]. Maternal adiposity has also been associated with increased amounts of nonglucose monosaccharides [9] and with higher milk fat and lactose, whereas total protein concentration seems to be unaffected $[10,11]$. However, there is limited information about a possible influence on protein or peptide distribution.

Digestion of nutrients is an essential function step for the newborn to allow normal growth and development. Both, the supply of essential amino acids and the bioactivities of milk proteins are dependent on their digestibility: some proteins act only in the intact form, others in the form of larger or small peptides formed during digestion, and some are completely digested and serve as a source of amino acids [4]. Interesting data about healthy full term infant digestion have been reported in the last years. Some works point to the role of digestion kinetics on the distinct effect of breastfed and infant formula fed infants [12]. Many factors, such as the type of food matrix (liquid/solid), $\mathrm{pH}$, the enzyme secretion, peristaltic movements and emptying of the stomach need to be considered in mimicking digestion [13]. In order to set relevant infant digestive conditions, outcomes from these models should be contrasted with in vivo data, for example, with regards to protein regions resistant to digestion. Peptidomics has allowed the identification of peptides deriving from many milk proteins in the gastric and intestinal aspirates of the newborns after their mother's milk ingestion [14-16].

The objective of this study was to evaluate the protein profile of a set of human milks from normal weight $(\mathrm{NW})$ and overweight/obese $(\mathrm{OW} / \mathrm{Ob})$ mothers to identify differences in protein expression in colostrum, transitional and mature milk. In addition, these milk samples were subjected to an in vitro static digestion model that takes into account the specificities of the gastrointestinal conditions of full-term newborn infants. The protein digestion products have been compared with available data from the digestive contents in newborns. The protein fraction of milk at diverse stages of lactation and the peptides released after digestion have been used to evaluate the influence of the mother's condition on its composition.

\section{Materials and Methods}

\subsection{Subjects and Samples}

Human milk samples were provided by participating mothers in a study conducted in the Obstetrics and Gynecology Department of "Hospital Universitario Virgen de las Nieves" from Granada (Spain). Ethics were approved by the relevant scientific committee and the trial was registered at ClinicalTrials.gov (accessed on 15 April 2019) (number NCT): NCT02811172. Details of the study were explained to all mothers who voluntarily gave written consent to participate. Eighteen lactating women were recruited for HM collection, with each mother donating three samples (colostrum, transitional and mature milk). The main characteristics of sampled mothers are shown in Table 1. Colostrum corresponded to milk from the 3rd to the 5th post-partum day, transitional milk to days 9-13 and mature milk from day 17 thereafter. Mothers with BMI in the $18.5-24.9 \mathrm{~kg} \mathrm{~m}^{-2}$ range were included in the NW group while those with a BMI greater than $25.0 \mathrm{~kg} \mathrm{~m}^{-2}$ were included in the $\mathrm{OW} / \mathrm{Ob}$ group. All human milk samples collected from the participants in sterile tubes were aliquoted and immediately stored at $-80^{\circ} \mathrm{C}$ until used.

\subsection{MALDI-TOF Protein Profile}

Milk was centrifuged at $11,000 \times g$ for 20 min at $4{ }^{\circ} \mathrm{C}$ for skimming. The skimmed milk was subsequently diluted 1:100 with ultrapure water (Milli-Q Millipore) and subjected to mass spectrometry analysis. An aliquot $(1 \mu \mathrm{L})$ of skimmed milk was directly spotted onto an MSP 96 polished steel target (Bruker Daltonics, Bremen, Germany), overlaid with $1 \mu \mathrm{L}$ of sinapinic acid matrix, in $50 \%$ acetonitrile, containing $0.1 \%$ trifluoroacetic acid $(v / v)$ and allowed to dry at room temperature, and analyzed on an Autoflex speed instrument 
(Bruker Daltonics, Bremen, Germany) using previously reported conditions [17]. Three independent spectra for each skimmed milk's fraction were collected in the automated mode, externally calibrated by using the Bacterial Test Standard (Bruker Daltonics, Bremen, Germany) and subsequently analyzed with the FlexAnalysis version 3.3 (Bruker Daltonics, Bremen, Germany) for the quality checking on raw data.

Table 1. Demographic description of study mothers and delivery characteristics by group.

\begin{tabular}{cccc}
\hline Characteristics & Normal Weight $^{\mathbf{a}}(\mathbf{N}=\mathbf{9 )}$ & Overweight/Obese $^{\mathbf{a}}(\boldsymbol{N}=\mathbf{9 )}$ & $\boldsymbol{p}$-Value \\
\hline Age, years & $33.0(5.5)$ & $32.0(5.0)$ & 0.8642 \\
Colostrum collection, days postpartum & $4.0(1.0)$ & $5.0(1.0)$ & 0.1340 \\
Transitional milk collection, days postpartum & $9.5(1.0)$ & $10.3(1.3)$ & 0.1970 \\
Mature milk collection, days postpartum & $19.0(3.0)$ & $19.0(0.8)$ & 0.6445 \\
Gestational age, days & $278.0(14.0)$ & $282.0(10.8)$ & 0.2162 \\
BMI early pregnancy, kg m ${ }^{-2}$ & $21.45(1.36)$ & $30.53(7.88)$ & 0.0012 \\
BMI at delivery, $\mathrm{kg} \mathrm{m}^{-2}$ & $25.95(2.39)$ & $34.23(3.64)$ & 0.0047 \\
Weight gain, $\mathrm{kg}^{\text {Newborn weight, } \mathrm{kg}}$ & $12.0(4.5)$ & $11.5(4.5)$ & 0.7576 \\
Gender distribution, $\%$ & $3.23(0.40)$ & $3.44(0.38)$ & 0.2343 \\
Female & & & 50 \\
Male & 43 & 50 & \\
\hline
\end{tabular}

BMI: Body Mass Index; ${ }^{a}$ Median (Interquartile range) ${ }^{\text {b }}$ Mann-Whitney test.

MALDI-TOF spectra were analyzed with ClinProTools (Version 2.2, Bruker Daltoics, Bremen, Germany) for statistical treatment. Baseline was subtracted using the Top Hat algorithm with $10 \%$ of minimal baseline width, and spectra were smoothed using the Savitsky-Golay algorithm with one cycle of $5 \mathrm{~m} / \mathrm{z}$ width. Peak picking was calculated on total average spectrum with a signal-to-noise of 3 and $5 \%$ of relative threshold base peak. Principal component analysis (PCA) was calculated to visualize samples projection on the score plot and the variables explaining the projection of the loading plot. Supervised analysis consisted in model calculation with three complementary algorithms. The quick classifier (QC) algorithm uses the statistical differences between classes to discriminate them. The peaks included in the calculation were thus selected according to their $p$-value after an automatic detection of peak number. The supervised neural network (SNN) algorithm is an iterative method based on the characteristics of data distribution [18]. The number of peaks involved in the calculation and the number of prototype detection were determined automatically by the algorithm. The genetic algorithm (GA) is a random algorithm that mimics the natural evolution [19]. Each spectrum is considered as a chromosome and each peak as a gene, and the overall principle is to recover the family belonging, meaning the class discrimination. For these three models, internal validation was calculated to ensure the calculation reliability, using $20 \%$ of the spectral data selected randomly and 10 iterations.

\subsection{In Vitro Simulated Gastrointestinal Digestion}

The infant gastrointestinal static in vitro model was carried out following the protocol described by Ménard et al. [20]. The gastrointestinal in vitro simulation included two consecutive steps: a gastric phase $\left(60 \mathrm{~min}\right.$ at $37^{\circ} \mathrm{C}$ with pepsin and lipase at $\mathrm{pH}$ 5.3) and an intestinal phase $\left(60 \mathrm{~min}\right.$ at $37^{\circ} \mathrm{C}$ with porcine pancreatin and bile at $\mathrm{pH}$ 6.6). Enzyme activity and bile concentration were measured according to the assays described by Brodkorb et al. (2019) [21]. Pepsin and gastric lipase were added as rabbit gastric extract (RGE). The added amount of RGE covered $100 \%$ of lipase activity and $120 \%$ of pepsin activity $(320 \mathrm{U} / \mathrm{mL})$. Samples were withdrawn at 5, 15, 30 and 60 min during gastric digestion and the reaction was stopped by adjusting the $\mathrm{pH}$ at 7.0 with $\mathrm{NaOH} 1 \mathrm{M}$ and snap freezing in liquid nitrogen. The intestinal phase was carried out by mixing the final gastric volume with an appropriate amount of simulated intestinal fluid, containing pancreatin from porcine pancreas, which covered the lipase $(90 \mathrm{U} / \mathrm{mL})$ and trypsin $(16 \mathrm{U} / \mathrm{mL})$ activity 
required of intestinal content, and porcine bile extract $3.1 \mathrm{mM}$ and the $\mathrm{pH}$ was adjusted to the intestinal $\mathrm{pH}$ of 6.6 using $\mathrm{HCl} 1 \mathrm{M}$. Samples were withdrawn at 5, 20 and 60 min during intestinal digestion and the reaction was stopped by snap freezing in liquid nitrogen. All samples were lyophilized and stored at $-20{ }^{\circ} \mathrm{C}$ until analysis. Nitrogen contents at the end of the gastric and intestinal phase were determined by elemental analysis.

\subsection{Sodium Dodecyl Sulphate-Polyacrylamide Gel Electrophoresis (SDS-PAGE) and Identification of Bands by In-Gel Digestion}

Undigested (control) and digested human milk samples were dissolved at $1 \mathrm{mg}$ of protein/mL in sample buffer and analyzed on $12 \%$ Bis-Trispolyacrilamide gels (Criterion_XT, Bio-Rad, Hercules, CA, USA). In gel digestion and analysis on an Autoflex speed MALDI-TOF/TOF (Bruker Daltonics, Bremen, Germany) instrument was performed as previously reported [22]. MASCOT v2.4 software (MatrixScience, Boston, MA, USA) was used to carry out protein identification searches against a homemade database of human milk proteins selected from the Uniprot database (https: / / www.uniprot.org/ accessed on 15 April 2019).

\subsection{Analysis by Ultra-Performance Liquid Chromatography (UPLC)}

Human milk proteins were separated by reverse-phase UPLC following an adaptation from Visser et al. (1991) [23] on an Aquity UPLC (Waters Technologies, Cerdanyola del Vallès, Spain). Solvent A was acetonitrile-water-trifluoroacetic acid (100:900:1 v/v/v) and solvent B was the same mixture with the proportions 900:100:0.1 (v/v/v). The analytical column was a Phenomenex AerisTM $3.6 \mu \mathrm{m}$ Widepore XB-C18 $(150 \mathrm{~mm} \times 2.1 \mathrm{~mm})$. Briefly, $100 \mu \mathrm{L}$ of human milk or digested sample were mixed with $100 \mu \mathrm{L}$ of $0.02 \mathrm{M} 1,3$ bis[tris(hydroxymethyl)methylamino] propane (Bis-Tris) buffer ( $\mathrm{pH} 7$ ) containing $8 \mathrm{M}$ urea and $0.3 \%$ of 2 -mercaptoethanol. After standing at room temperature for $1 \mathrm{~h}$, samples were diluted (four-fold for human milk/gastric samples and two-fold for intestinal samples) with solvent A containing $6 \mathrm{M}$ urea, and centrifuged at $13,000 \times g 5$ min before injection of the supernatant.

\subsection{Analysis of Digests by HPLC-Tandem Mass Spectrometry (HPLC-MS/MS)}

Freeze-dried samples were reconstituted in ammonium carbonate $\left(\mathrm{NH}_{4} \mathrm{CO}_{3}\right) 25 \mathrm{mM}$ and treated for $60 \mathrm{~min}$ at $37^{\circ} \mathrm{C}$ with 1,4-dithiothreitol $140 \mathrm{mM}(1: 1, v / v)$ (Sigma-Aldrich, St. Louis, MO, USA) to reduce disulfide linkages in order to improve the identification. Samples were analyzed by HPLC-MS/MS in duplicate using an Agilent 1100 HPLC system (Agilent Technologies, Waldbron, Germany), equipped with a Mediterranean Sea18 column (150 mm $\times 2.1 \mathrm{~mm}$, Teknokroma, Barcelona, Spain) connected to an Esquire 3000 linear ion trap mass spectrometer (Bruker Daltonics $\mathrm{GmbH}$, Bremen, Germany) as previously described [24]. The spectra were recorded over the $m / z$ ranges $100-700,100-1700$ and 100-2000, selecting 500, 750 and 1200 as target mass, respectively. A homemade database of most abundant human milk proteins was used for the peptide sequencing in MASCOT v2.4 software. No specific enzyme cleavage was used. Peptide mass tolerance was set to $0.1 \%$ and 0.5 Da for MS and MS/MS analysis, respectively. Biotools version 3.2 (Bruker Daltonics, Bremen, Germany) was used for the interpretation of the matched MS/MS spectra. The list of peptides appearing in the selected number of subjects was compiled through Venn diagrams using the Venny tool [25]. The representation of the peptide profile was performed with Peptigram [26]. Bioactive sequences were searched in the MPDB (Nielsen, New York, NY, USA). With the identified peptides after simulated digestion, hierarchical clustering trees were built and optimized using the PermutMatrix software version 1.9.3.0 [27]. The mean center rows were used as datasets, and Ward's dissimilarity aggregation procedure based on Pearson distance was used. 


\section{Results and Discussion}

\subsection{Protein Profile of Human Milks by MALDI-TOF Mass Spectrometry}

The profile of individual milks counting large peptides and small proteins was examined by MALDI-TOF mass spectrometry. The spectra from colostrum, transitional milk and mature milk from mothers corresponding to the different BMI groups, NW (Figure 1) and $\mathrm{OW} / \mathrm{Ob}$ subjects (Figure 2) were first contrasted. In the gel-like view of human colostrum, transitional milk and mature milk of all individual spectral data are shown as lines and the grey level represents the peak intensity, which permits to visualize individual variability. In contrast, the spectrum view represents the average profile from all samples. In the protein profile, the main peak around $14 \mathrm{kDa}$ corresponds to $\alpha$-LA, although adjacent small signals can be ascribed to lysozyme $\mathrm{C}$ and other less abundant proteins in human milk. Besides, many peaks in the range 2000-10,000 Da characterize all samples, although species between 3000 and $4500 \mathrm{Da}$ were more intense in colostrum and transitional milk. In mature milks, peak intensity was comparatively lower, which is compatible with inferior relative protein content. It is known that the protein content of human milk decreases rapidly during the first month of lactation, and declines more slowly after that $[4,28]$. In spite of the use of sinapinic acid matrix, which favors the ionization of high molecular weight proteins, the intensity of peaks above $m / z$ ratio of 15,000 , where caseins should appear, was very low. An impaired detection of higher mass-range species in human milk under 30 days post-partum was previously reported under similar conditions [17].
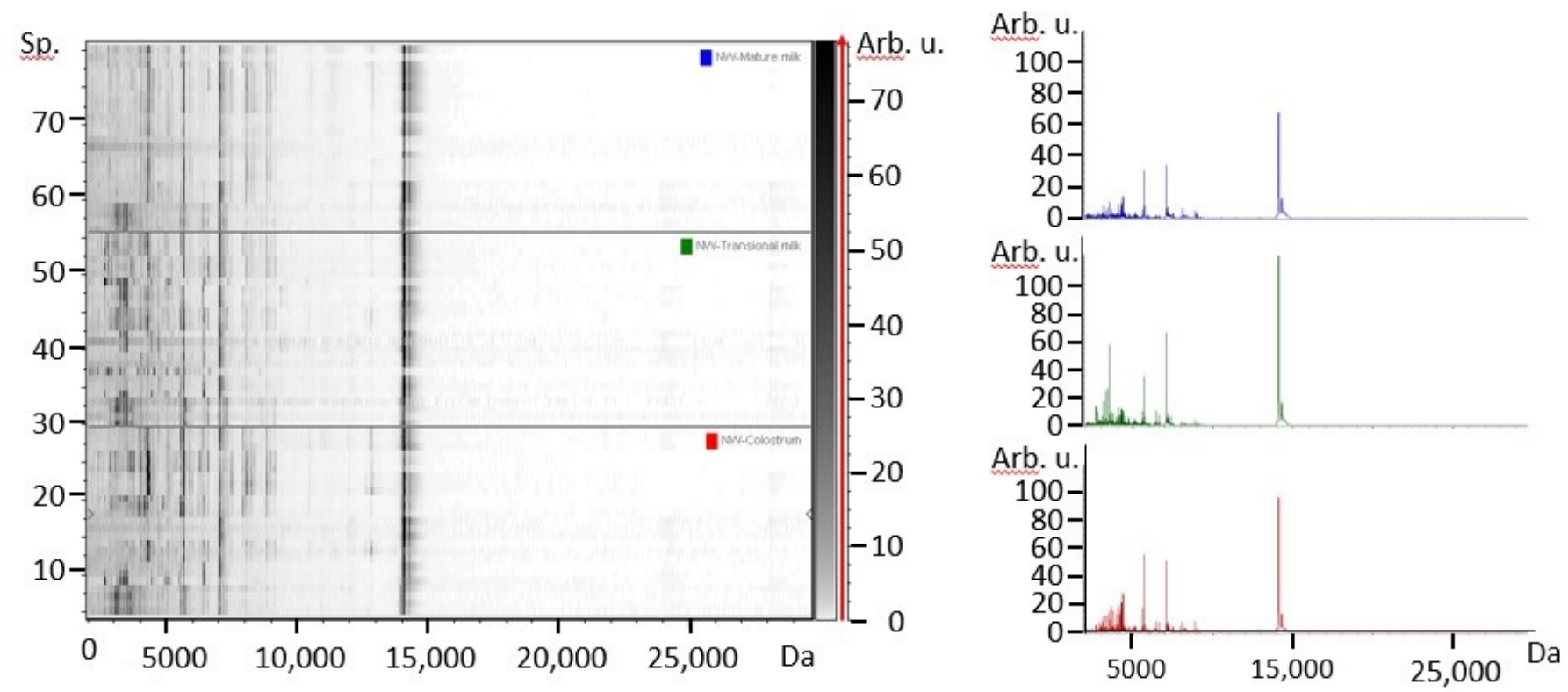

(a)

Figure 1. Cont. 


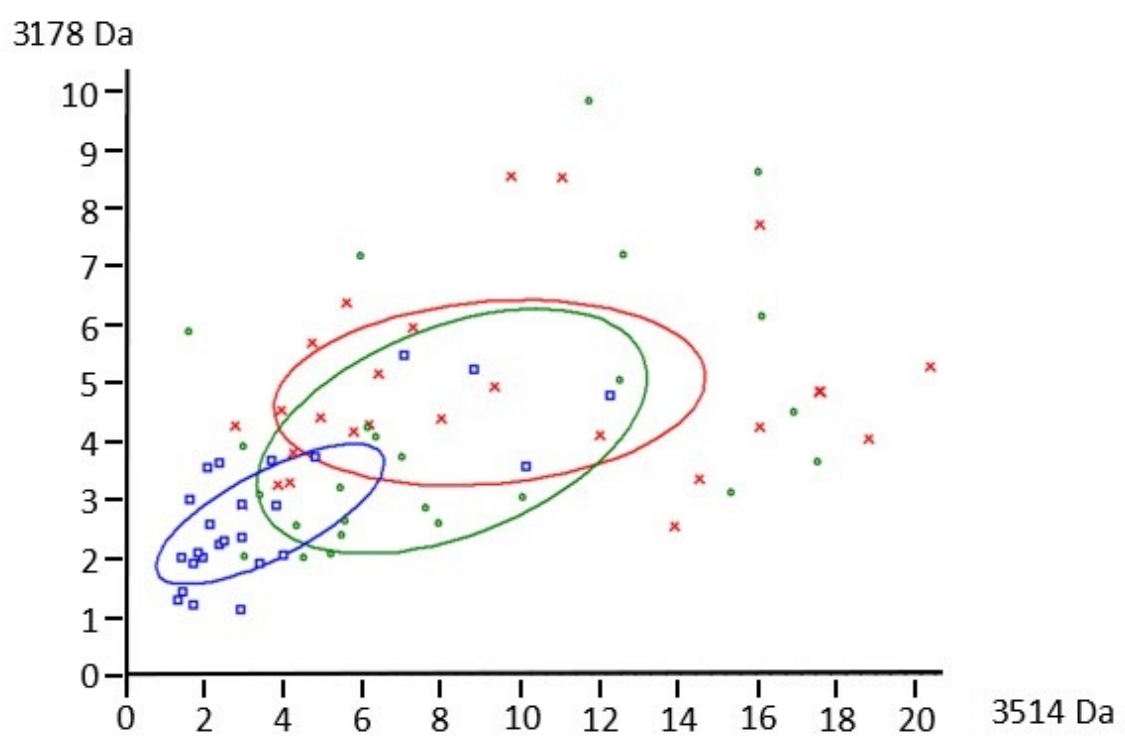

(b)

Figure 1. (a) Gel-like view and average spectrum. (b) 2D-plot protein spectra according to the intensities of $m / z 3178$ and $m / z 3514$ from colostrum (red), transitional milk (green) and mature milk (blue) from NW mothers. Number of points $=72$ (8 subjects, 3 milk types, 3 replicates).

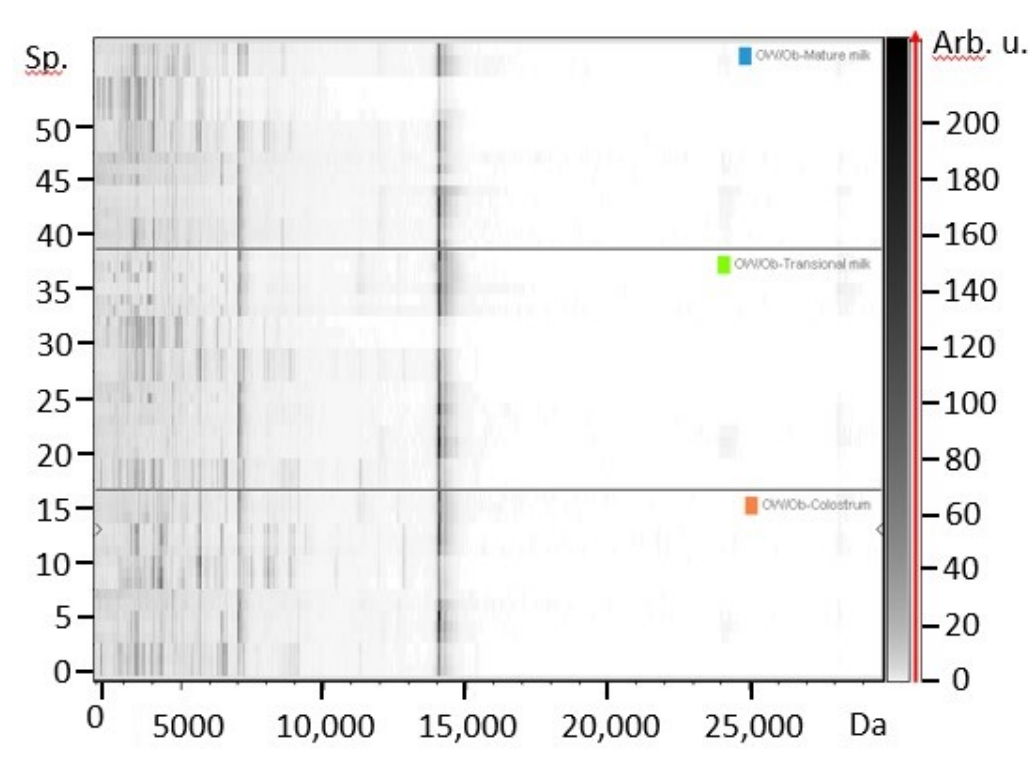

Arb. u.
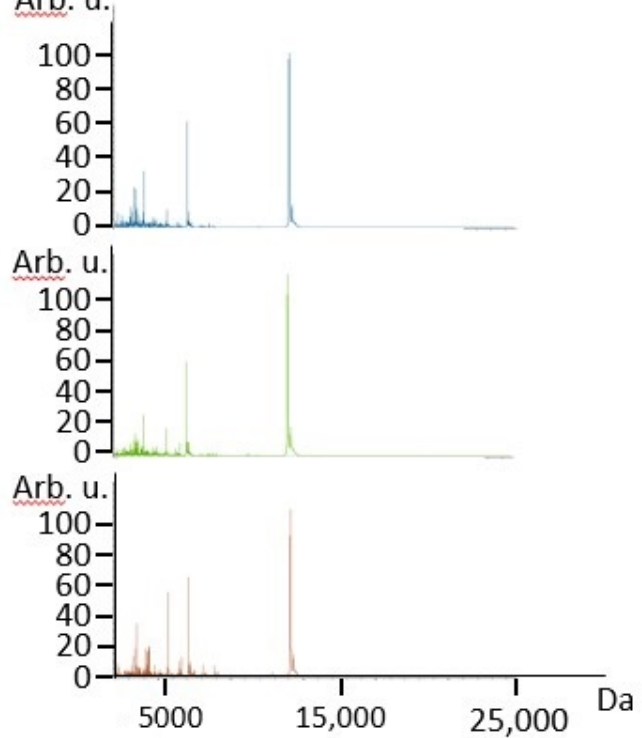

(a)

Figure 2. Cont. 


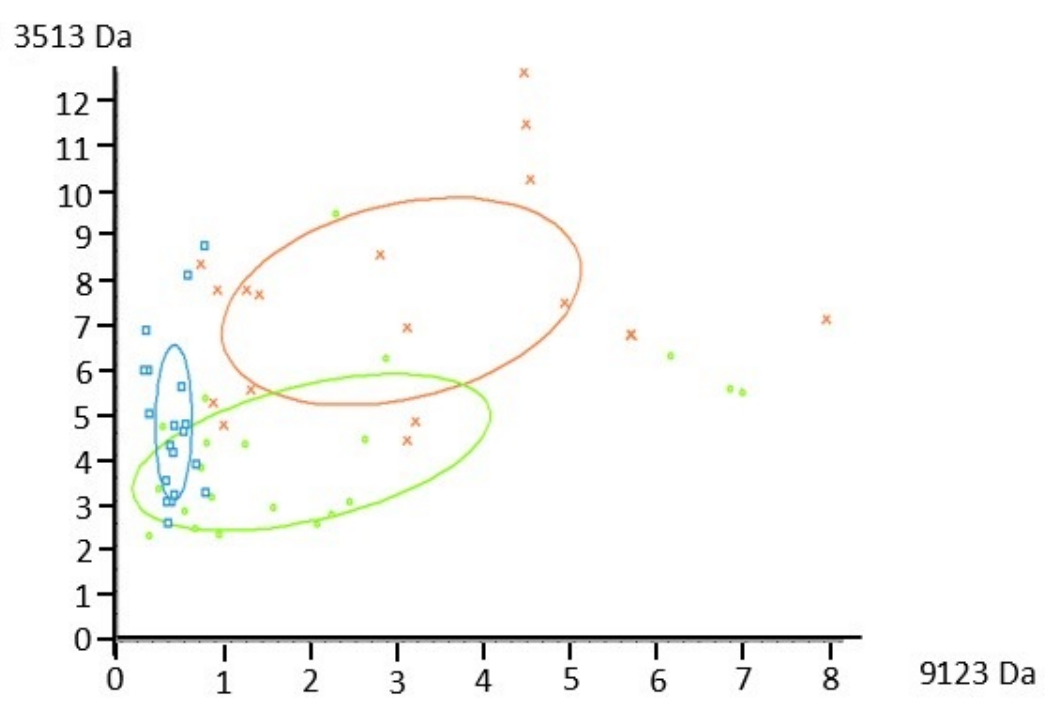

(b)

Figure 2. (a) Gel-like view and average spectrum. (b) 2D-plot protein spectra according to the intensities of $m / z 3513$ and $m / z 9123$ from colostrum (light red), transitional milk (light green) and mature milk (light blue) from OW/Ob mothers. Number of points $=54$ (6 subjects, 3 milk types, 3 replicates).

The effect of the lactation time in the protein profile was assessed by studying samples of colostrum, transitional milk and mature milk from $8 \mathrm{NW}$ and $6 \mathrm{OW} / \mathrm{Ob}$ mothers. A representation of the three milk types is shown for each group in the form of 2D-plot according to the two peaks with highest variance (Figure $1 \mathrm{~b}$ or Figure $2 \mathrm{~b}$ ). Consistent with other measurements, the interindividual variation is considerable, although dispersion was lower for mature milk compared to both colostrum and transitional milk. However, an evolution from colostrum to mature milk can be observed in both groups. Less spreading was observed in the $\mathrm{OW} / \mathrm{Ob}$ group, in spite of a lower number of subjects.

A second design was used to study the effect of the mother BMI condition in the protein profile of the expressed mature milk. Combined spectra from $9 \mathrm{NW}$ and $9 \mathrm{OW} / \mathrm{Ob}$ subjects were used to determine the state of classification in the first three principal components (PC) (Figure 3). The PCA analysis showed that the mature milk profiles clustered together, with certain individuals from both classes being slightly separated. The contributions of PC1, PC2 and PC 3 to the generation of profile explained less than $30 \%$ of the variance. However, the 2D-plot representation according to the intensities of $\mathrm{m} / \mathrm{z} 4244$ and $m / z 4322$ grouped $\mathrm{OW} / \mathrm{Ob}$ and NW separately, with a tighter grouping in the case of OW/Ob mothers. These two masses corresponded to well defined signals present in all samples and merit attention as possible biomarkers. A predictive model generation with different algorithms was used to evaluate the discrimination potential of the protein profile. The QC algorithm provided $83.44 \%$ recognition capability with a cross validation of $76.61 \%$, the signal corresponding to mass 4322 being selected in the integration region for classification. The application of the models based on the SNN and GA provided higher rates, with cross validation values of 79.77 and $78.98 \%$, and recognition capability percentages of 96.49 and $98.21 \%$, respectively, the GA providing $100 \%$ recognition capability for class $2(\mathrm{OW} / \mathrm{Ob})$. The list of masses involved in the model generation and their weight are shown in Table S1. 


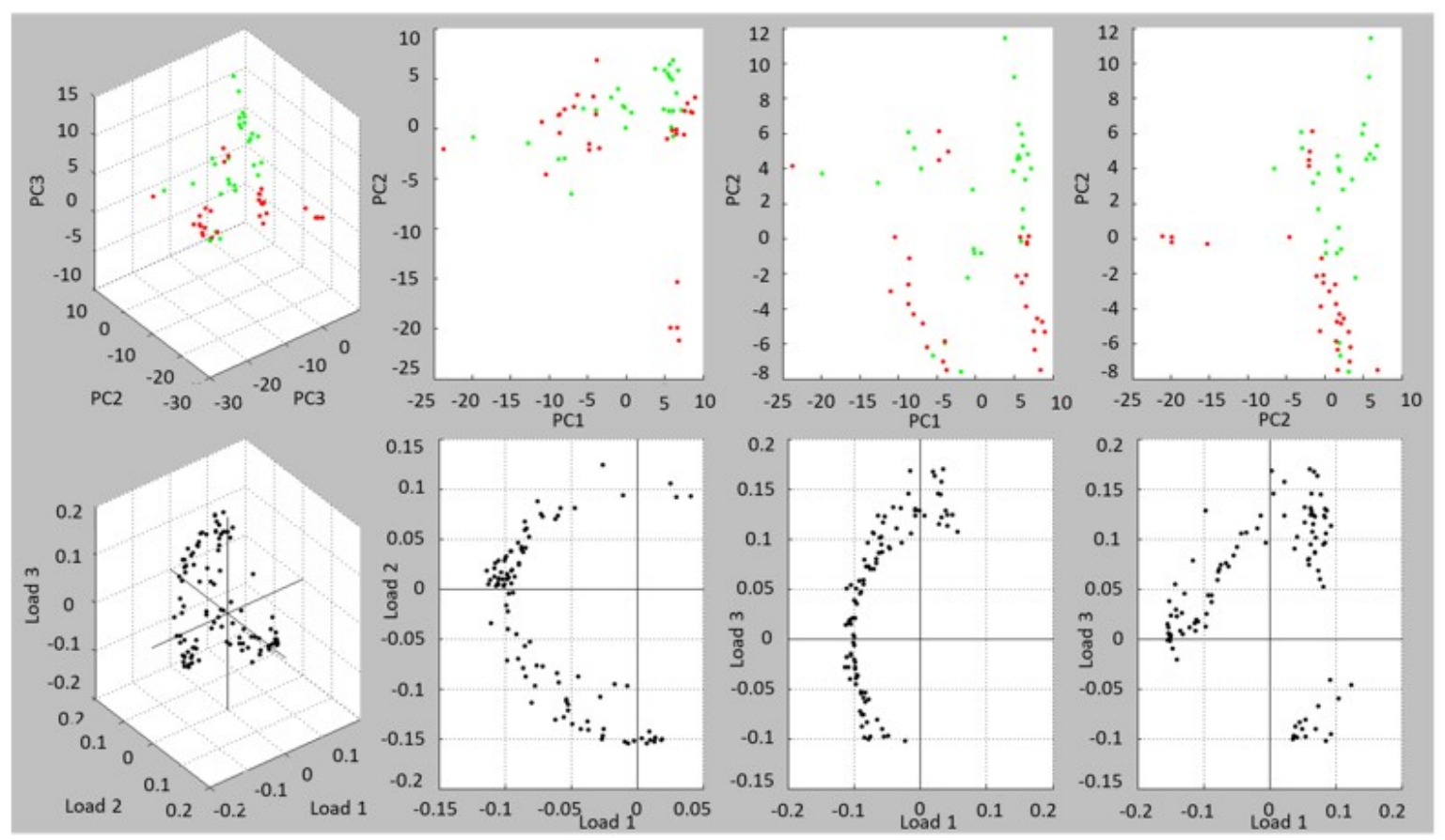

(a)

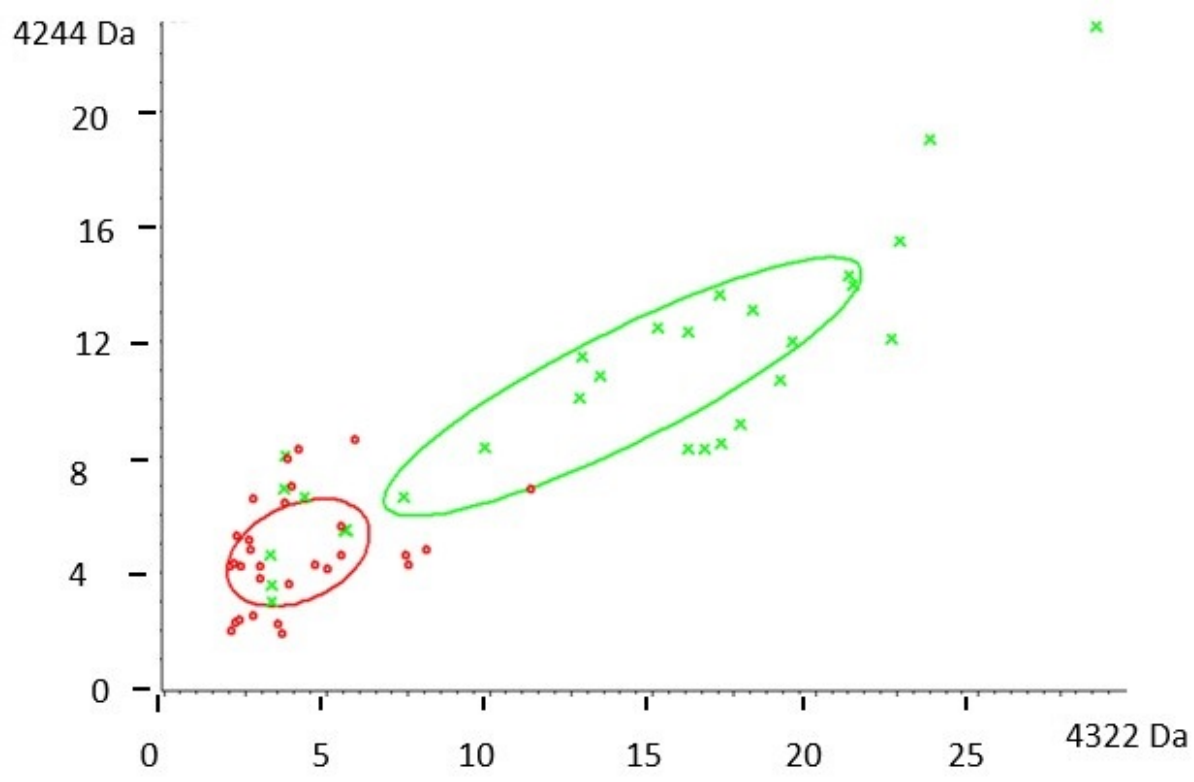

(b)

Figure 3. (a) PCA analysis contrasting spectral data of mature milks from NW (green) and OW/Ob (red) subjects. 3D view and combinations of the first three principal components. (b) 2D-plot protein spectra according to the intensities of $m / z$ 4244 and 4322. Number of points $=54$ (9 NW subjects, 9 OW/Ob subjects, 3 replicates).

This supervised analysis showed the ability of MALDI-TOF analysis to class with a high degree of confidence mature milks according to the mothers BMI. Recent studies relating breast milk with body composition have indicated that individual bioactive components of human milk may regulate different compartments of infant weight gain, i.e., adiposity or accumulation of lean mass, separately [29]. In fact, some studies correlate the adipokines content in breast milk with the respective levels in maternal and infant blood [30]. In this regard, it is still unknown how alterations in breast milk composition 
will subsequently impact later health outcomes. Delivered components as different as proteins, fatty acids or insulin have shown associations with infant fat mass gain [31]. The used strategy has allowed to evidence specific signals characterizing the mothers by BMI. Therefore, they might be useful to identify new biomarkers and complement these analyses in the way to discern the role of human milk composition in the infants' development.

\subsection{Protein Degradation of Human Milk during Infant In Vitro Gastrointestinal Digestion}

Ten mature milk samples, six from NW subjects and four from OW/Ob subjects, were submitted to in vitro gastrointestinal digestion under conditions that simulate those of the newborn. The SDS-PAGE electrophoretic pattern during gastrointestinal digestion of a milk sample from a NW donor is presented in Figure 4a. Digested samples from the gastric (G5, G15, G30 and G60) and intestinal (I5, I30 and I60) phases were compared with the undigested human milk (HM). The analysis of the gel bands by MALDI-MS/MS allowed identification of bile salt-activated lipase (BAL), lactoferrin, immunoglobulin heavy constant alpha 2 (IgHA2), $\beta$-casein and $\alpha$-LA. The whey proteins $\alpha$-LA and lactoferrin are major proteins in human milk, comprising $25-35 \%$ and $15-20 \%$ of the total protein content, respectively [32], as observed in the band size. Despite similar molecular weight than lactoferrin, $78 \mathrm{vs} .79 \mathrm{kDa}$, BAL shows a lower electrophoretic mobility, probably due to its mucin-like structure with extended conformation [33]. $\alpha$-LA and lactoferrin resisted gastric digestion at G60 due to the globular and compact structure. The caseins, especially $\beta$-casein, were hydrolyzed in some measure over gastric digestion, in accordance with their loose and flexible structure that makes them susceptible to pepsinolysis. All proteins were detected after $60 \mathrm{~min}$, consistent with the high gastric $\mathrm{pH}$ in infants (5.3) compared to the adult (3.0) that causes pepsin only be at $10 \%$ of its maximal activity. By contrast, intestinal digestion resulted in a rapid hydrolysis of the intact proteins remaining after the gastric step. After five min, the bands visible on the SDS-PAGE gel corresponded to the proteins added in the pancreatin, as previously observed [20].

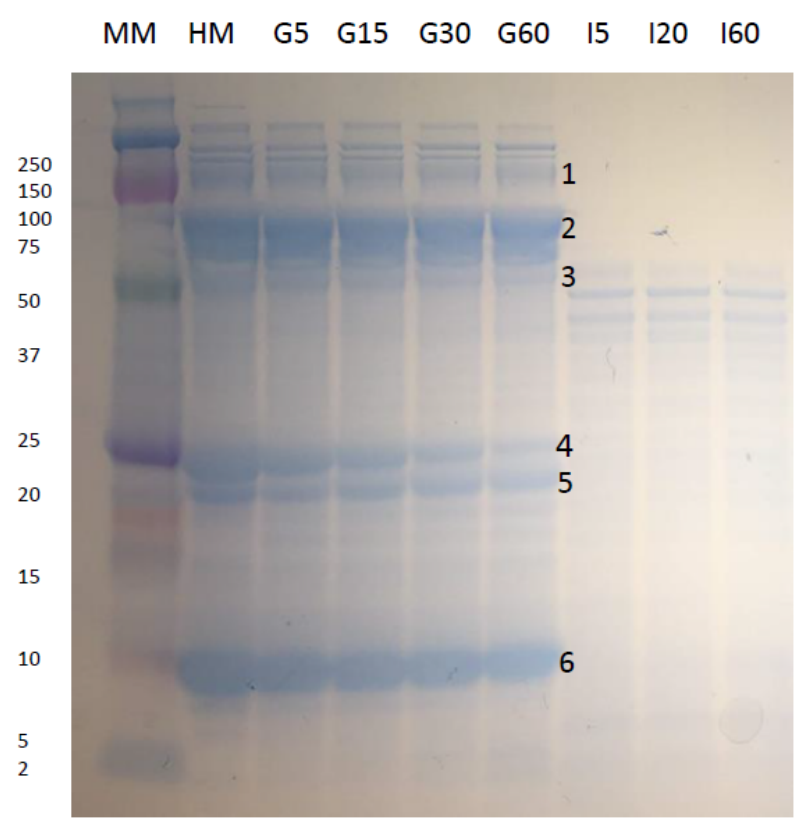

(a)

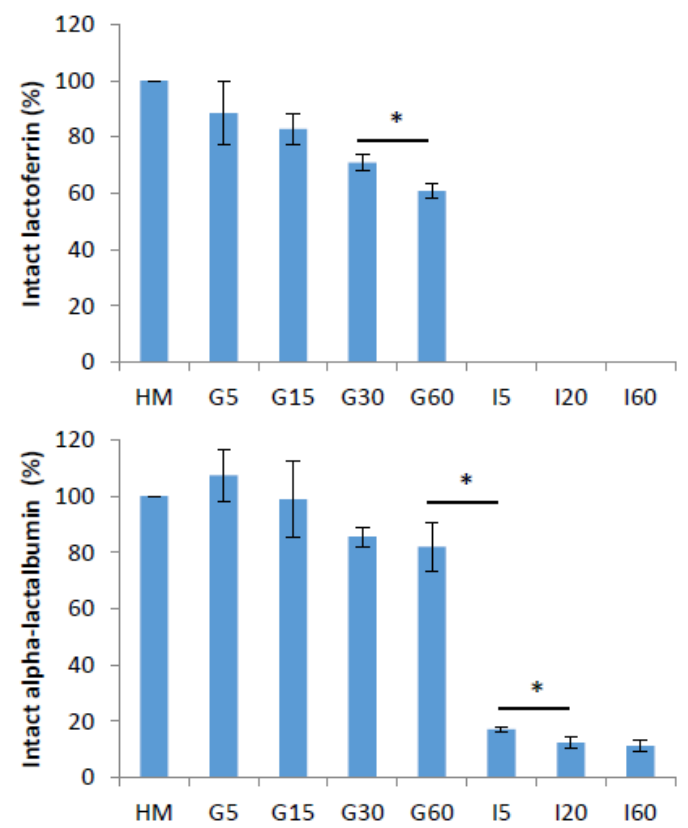

(b)

Figure 4. (a) SDS-PAGE profile of a mature milk sample submitted to in vitro gastrointestinal digestion. Band identification by tandem MS: 1 . Bile salt-activated lipase. 2. Lactoferrin. 3. Immunoglobulin heavy constant alpha 4. $\beta$-casein. 5. $\beta$ - and $\alpha$ s1-casein. 6. $\alpha$-LA. (b) Quantification of lactoferrin and $\alpha$-LA by UPLC $(n=4) .{ }^{*} p<0.05$ (t-test) MM: molecular marker; HM: human milk; gastric digestion time 5 (G5), 15 (G15), 30 (G30) and 60 (G60) min; intestinal digestion time 5 (I5), 20 (I20) and 60 (I60) $\mathrm{min}$. 
Human milk samples and in vitro digests were analyzed by UPLC to quantitatively determine the protein changes over digestion. Lactoferrin remained as $61 \%$ intact protein during the gastric phase with no protein being detected in the intestinal phase. $82 \%$ intact $\alpha$-LA was observed, while around $11 \%$ of the initial concentration was determined at the end of the intestinal digestion (Figure $4 \mathrm{~b}$ ). These results are similar to the percentage of $\alpha$-LA reported to be resistant to hydrolysis in the development of this digestion model $(86.7 \%)$, although an infant formula with bovine proteins was used [20]. Interestingly, De Oliveira et al. (2017) [34] determined the proteolysis of human milk proteins during gastric digestion of human milk by preterm infants. In that study, ca. $40 \%$ and $75 \%$ of lactoferrin and $\alpha$-LA, respectively, was found in the infant stomach after 90 min of ingestion, in good correspondence with the present values. The observed protein resistance might well mimic the full-term infant digestion, which is intended by this protocol, although full-term infant data of intact protein resistance should be contrasted when available.

Lactoferrin and IgA have a structure that makes them comparatively resistant to digestion. Furthermore, intact lactoferrin and IgA have been observed in stools of both preterm and term exclusively breastfed infants by immunological methods [35]. It is considered that only partial digestion of human lactoferrin takes place in the infant and this supports the beneficial effect of this abundant iron-binding protein in terms of bacteriostatic, bactericidal and antiviral activity. This report shows resistance of human lactoferrin under these gastric digestive conditions, in good correspondence with previous in vivo data. On the other hand, when comparing digestion of different human Ig in a dynamic simulated model, higher resistance of IgA and IgM has been reported compared to IgG, by means of proteomic techniques [36].

\subsection{Peptidomic Characterization of In Vitro Digests}

Human milk gastrointestinal digests were analyzed under equal conditions by HPLCMS/MS. The peptide trace from $\alpha$-LA, $\beta$-casein and lactoferrin was represented using the Peptigram tool. Figure 5 represents the peptides identified after the application of the gastric phase and the intestinal phase at both 5 and $60 \mathrm{~min}$. After the gastric digestion, only peptides from $\beta$-casein were identified, consistent with the resistance of $\alpha$-LA and lactoferrin. Gastrointestinal digests produced a pattern with higher number of peptides, with great similarity between 5 and $60 \mathrm{~min}$. However, more intense color in specific areas denotes greater number of overlapping identified peptides after $60 \mathrm{~min}$ for the three proteins. Calculated coverages reached 86,52 and $48 \%$ for $\beta$-casein, $\alpha$-LA and lactoferrin, respectively.

The peptides identified in the human milk gastrointestinal digests (endpoint at $60 \mathrm{~min}$ ) consistently derived from 20 proteins (Table 2). These proteins were considered representative because a similar number of released peptides were found in at least four subjects. Identified peptides arose, for the most part, from $\beta$-casein, $\alpha$-LA and lactoferrin, in accordance with their abundance in milk. Other predominantly precursor proteins were butyrophilin subfamily 1 member A1, BAL and IgAH2. From the human milk fat globule membrane, mucin-1, lactadherin and butyrophilin are three major components that gave rise to peptides under the used digestive conditions. It has been reported that mucin and lactadherin resist digestion in the stomach of milk-fed infants, while butyrophilin is rapidly degraded [37]. The number of peptides from the last protein in the digests can be ascribed to this rapid degradation.

The identified sequences were contrasted to those previously found upon analysis of the gastrointestinal tract content in infants [14,15,38] or in a suckling rat pup model [39], after human milk consumption. Ninety sequences from seven proteins found upon in vitro digestion were coincident with those reported in vivo. The complete list of identical peptides to those found in vivo is shown in Table S2. 

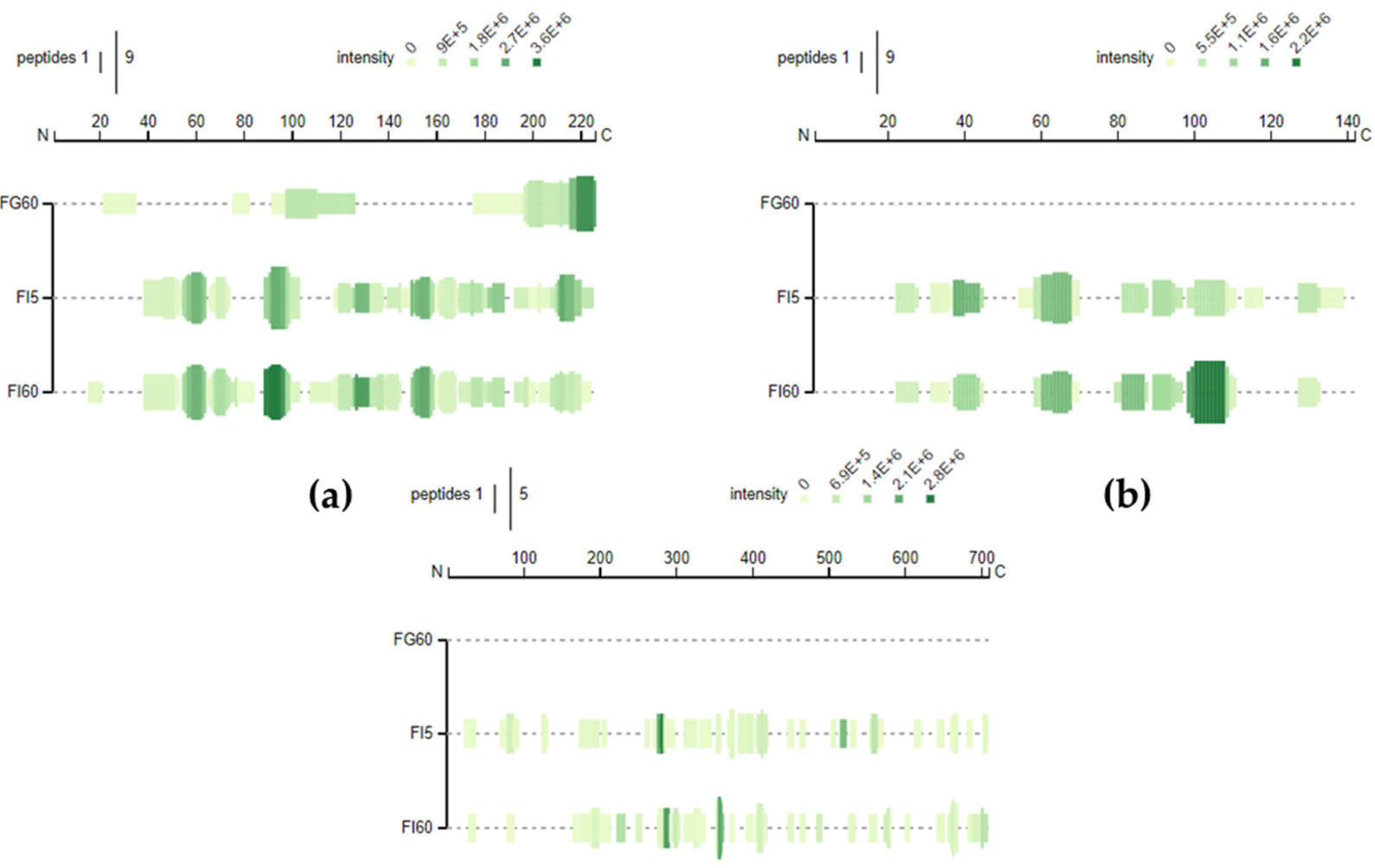

(b)

(c)

Figure 5. Peptigram profile of $\beta$-casein (a), $\alpha$-LA (b) and lactoferrin (c) derived peptides in digests of human milk ( $N=10)$ after $60 \mathrm{~min}$ gastric digestion (FG60), and $5 \mathrm{~min}$ (FI5) and $60 \mathrm{~min}$ (FI60) intestinal digestion.

Table 2. Number identified of peptides and corresponding proteins after individual in vitro digestion of breast milk from $\mathrm{NW}(\mathrm{N}=6)$ and $\mathrm{OW} / \mathrm{Ob}(N=4)$ subjects.

\begin{tabular}{|c|c|c|c|c|c|}
\hline Protein Name & $\begin{array}{c}\text { Accession } \\
\text { Number }\end{array}$ & $\begin{array}{c}\text { Peptides } \\
\text { Identified in Two } \\
\text { or More Subjects } \\
(N)\end{array}$ & $\begin{array}{l}\text { Mol. Weight, } \\
\text { Parent Protein } \\
\text { (kDa) }\end{array}$ & $\begin{array}{c}\text { Sequence } \\
\text { Length, Parent } \\
\text { Protein }\end{array}$ & $\begin{array}{c}\text { Score (Digest } \\
\text { Matches) }\end{array}$ \\
\hline$\beta$-casein & P05814 & 123 & 25.38 & 226 & 332.54 \\
\hline$\alpha_{\mathrm{s} 1}$-casein & P47710 & 26 & 21.67 & 185 & 46.73 \\
\hline K-casein & P07498 & 11 & 20.31 & 182 & 36.41 \\
\hline Lactotransferrin & P02788 & 121 & 78.18 & 710 & 103.31 \\
\hline$\alpha$-lactalbumin & P00709 & 61 & 16.23 & 142 & 277.99 \\
\hline Bile Salt-activated lipase & P19835 & 19 & 79.32 & 753 & 30.53 \\
\hline Immunoglobulin heavy constant alpha 2 & P01877 & 18 & 36.59 & 340 & 27.96 \\
\hline Butyrophilin subfamily 1 member A1 & Q13410 & 23 & 58.96 & 526 & 28.9 \\
\hline Polymericimmunoglobulin receptor & $\widehat{\mathrm{P}} 01833$ & 25 & 83.28 & 764 & 37.73 \\
\hline Tenascin & P24821 & 59 & 240.85 & 2201 & 29.5 \\
\hline Mucin-4 & Q99102 & 56 & 231.52 & 2169 & 38.42 \\
\hline Xanthine dehydrogenase/oxidase & P47989 & 44 & 146.42 & 1333 & 23.27 \\
\hline Receptor tyrosine-proteinkinase erbB- 4 & Q15303 & 29 & 146.81 & 1308 & 28.3 \\
\hline Osteopontin & P10451 & 19 & 35.42 & 314 & 24.96 \\
\hline Cadherin-1 & P12830 & 12 & 97.46 & 882 & 28.02 \\
\hline Clusterin & P10909 & 11 & 52.50 & 449 & 25.23 \\
\hline Galectin-3-binding protein & Q08380 & 9 & 65.33 & 585 & 24.74 \\
\hline Mucin-1 & P15941 & 8 & 122.10 & 1255 & 28.77 \\
\hline Zinc-alpha-2-glycoprotein & P25311 & 4 & 34.26 & 298 & 20.67 \\
\hline Plateletglycoprotein 4 & P16671 & 3 & 53.05 & 472 & 22.34 \\
\hline
\end{tabular}

The results from the individual digestions in terms of sequence and intensity of identified peptides were analyzed with software permitting the visualization of the possible associations. Identified peptides derived from $\alpha$-LA, lactoferrin and $\beta$-casein were used 
to construct a dendrogram (Figure 6). The peptide fingerprint from digests did not discriminate the samples by the donor BMI, indicating that the peptide profile after in vitro digestion reduces the differences observed in the protein fraction. On one side, this can be attributed to digestion bringing closer the protein features of differing milk classes. On the other side, it might also be the case that resistant peptides are not those responsible for the differences. Discriminating peptides might have been degraded, or be too large to be detected by the proteomic approach employed. Lastly, identical (in vitro) gastrointestinal conditions have been applied to the samples but the impact of differing milk composition on the individual digestive behavior is still unknown and is worthy of future studies.

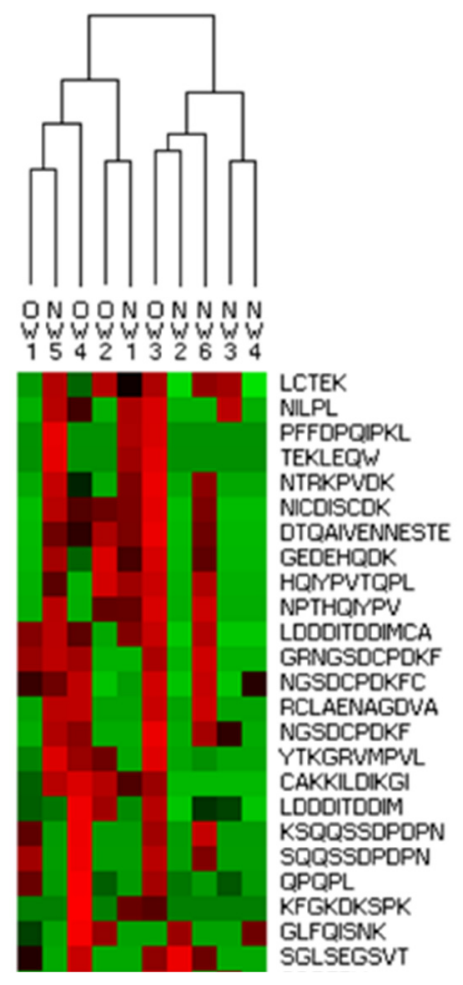

Figure 6. Heat map representation (fragment) of the hierarchical clustering analysis of peptides identified after in vitro digestion of breast milk. Columns correspond to subjects included in the overweight/obese group or normal weight group. Rows correspond to intensity of sequences derived from $\beta$-casein, $\alpha$-lactalbumin and lactoferrin identified in at least 3 subjects. Complete figure in Figure S1.

Although the number of subjects is acknowledged as a limitation, this study provides novel tools to depict the protein/peptide fraction of human milk, which can be used in nutritional studies intended to associate milk composition with the physiological status while nursing.

\section{Conclusions}

Human milk contains a multitude of proteins, with a dynamic composition varying along lactation time. The applied MALDI-TOF analysis has proved effective as a tool to associate the effect of the lactation stage with the protein profile of the expressed milk in both NW and $\mathrm{OW} / \mathrm{Ob}$ subjects, lower dispersion being found in the second group. Moreover, the mothers BMI could be predicted using the variations in the $4322 \mathrm{~m} / \mathrm{z}$ signal. The study of a larger amount of subjects might contribute to identify biomarkers making it possible to associate the breast milk composition with metabolic features in the mother and later health outcomes in the offspring. The newborn digestion model results in a resistance of most abundant human whey proteins, $\alpha$-LA and lactoferrin, similar to the observed 
in vivo. Likewise, proteins ascribable to the undegraded peptides and a large number of specific sequences closely resemble those previously found in newborn digests after human milk consumption. Therefore, important outcomes after passage of human milk through the gastrointestinal tract can be predicted using the infant model. It remains to elucidate if the different protein composition might have physiological significance for the newborn.

Supplementary Materials: The following are available online at https:/ /www.mdpi.com/article/10 .3390 /foods10040887/s1, Table S1: MALDI-TOF signals provided by the predictive model generation. Effect of the mother condition (NW vs OW/Ob), Table S2: Identified peptides matching sequences previously observed in the gastrointestinal content of newborns or a rat pup model after human milk consumption, Figure S1: Complete heat map representation of the hierarchical clustering analysis of peptides identified after in vitro digestion of breast milk. Columns correspond to subjects included in the overweight/obese group or normal weight group. Rows correspond to intensity of sequences derived from $\beta$-casein, $\alpha$-lactalbumin and lactoferrin identified in at least 3 subjects.

Author Contributions: The author's responsibilities were as follows: conceptualization B.M., I.R.; formal analysis S.S.-H., L.T., P.J.-B.; investigation S.S.-H., P.J.-B.; writing—original draft preparation S.S.-H., B.M.; writing-review and editing B.M., I.R., L.T.; supervision B.M., I.R., M.O.-H. All authors have read and agreed to the published version of the manuscript.

Funding: This project was supported by project PID2019-107663RB-I00 from Ministry of Science and Innovation (MICINN). S.S.-H. is the recipient of FPU grant (FPU15-04549) from the Spanish Ministry of Education, Culture and Sports.

Institutional Review Board Statement: The study was approved by the Ethics Committee of Hospital Universitario Virgen de las Nieves, Granada (SPID201600X080546IV0, 23 June 2016).

Informed Consent Statement: Informed consent was obtained from all subjects involved in the study.

Acknowledgments: The authors thank the volunteers who made the study possible through their participation and collaboration. This paper and results presented constitute part of the thesis of Silvia Sánchez Hernández, which is being carried out within the Nutrition and Food Science Doctorate Program at the University of Granada.

Conflicts of Interest: The authors declare no conflict of interest regarding the publication of this manuscript.

\section{References}

1. Butte, N.F.; Lopez-Alarcon, M.G.; Garza, C. Nutrient Adequacy of Exclusive Breastfeeding for the Term Infant During the First Six Months of Life; WHO: Geneva, Switzerland, 2002; Available online: https:/ / apps.who.int/iris/handle/10665/42519 (accessed on 14 February 2018).

2. Lönnerdal, B. Bioactive Proteins in Human Milk: Health, Nutrition, and Implications for Infant Formulas. J. Pediatr. 2016, 173, S4-S9. [CrossRef]

3. Zepf, F.D.; Rao, P.; Moore, J.; Stewart, R.; Ladino, Y.M.; Hartmann, B.T. Human breast milk and adipokines-A potential role for the soluble leptin receptor (sOb-R) in the regulation of infant energy intake and development. Med. Hypotheses 2016, 86, 53-55. [CrossRef] [PubMed]

4. Lönnerdal, B. Infant formula and infant nutrition: Bioactive proteins of human milk and implications for composition of infant formulas. Am. J. Clin. Nutr. 2014, 99, 712S-717S. [CrossRef] [PubMed]

5. Liao, Y.; Weber, D.; Xu, W.; Durbin-Johnson, B.P.; Phinney, B.S.; Lönnerdal, B. Absolute Quantification of Human Milk Caseins and the Whey/Casein Ratio during the First Year of Lactation. J. Proteome Res. 2017, 16, 4113-4121. [CrossRef]

6. Ren, Q.; Zhou, Y.; Zhang, W.; Tian, Y.; Sun, H.; Zhao, X.; Xu, Y.; Jiang, S. Longitudinal changes in the bioactive proteins in human milk of the Chinese population: A systematic review. Food Sci. Nutr. 2021, 9, 25-35. [CrossRef] [PubMed]

7. Ahuja, S.; Boylan, M.; Hart, S.L.; Román-Shriver, C.; Spallholz, J.E.; Pence, B.C.; Sawyer, B.G. Glucose and Insulin Levels are Increased in Obese and Overweight Mothers' Breast-Milk. Food Nutr. Sci. 2014, 2, 201-206. [CrossRef]

8. Andreas, N.J.; Hyde, M.J.; Gale, C.; Parkinson, J.R.C.; Jeffries, S.; Holmes, E.; Modi, N. Effect of Maternal Body Mass Index on Hormones in Breast Milk: A Systematic Review. PLoS ONE 2014, 9, e115043. [CrossRef]

9. Saben, J.L.; Sims, C.R.; Piccolo, B.D.; Andres, A. Maternal adiposity alters the human milk metabolome: Associations between nonglucose monosaccharides and infant adiposity. Am. J. Clin. Nutr. 2020, 112, 1228-1239. [CrossRef]

10. Young, B.E.; Patinkin, Z.; Palmer, C.; De La Houssaye, B.; Barbour, L.A.; Hernandez, T.; Friedman, J.E.; Krebs, N.F. Human milk insulin is related to maternal plasma insulin and BMI: But other components of human milk do not differ by BMI. Eur. J. Clin. Nutr. 2017, 71, 1094-1100. [CrossRef] 
11. Leghi, G.E.; Netting, M.J.; Middleton, P.F.; Wlodek, M.E.; Geddes, D.T.; Muhlhausler, B.S. The impact of maternal obesity on human milk macronutrient composition: A systematic review and meta-analysis. Nutrients 2020, 12, 934. [CrossRef]

12. Bourlieu, C.; Deglaire, A.; de Oliveira, S.C.; Ménard, O.; Le Gouar, Y.; Carrière, F.; Dupont, D. Towards infant formula biomimetic of human milk structure and digestive behaviour. OCL 2017, 24, D206. [CrossRef]

13. Devle, H.; Ulleberg, E.K.; Naess-Andresen, C.F.; Rukke, E.O.; Vegarud, G.; Ekeberg, D. Reciprocal interacting effects of proteins and lipids during exvivo digestion of bovine milk. Int. Dairy J. 2014, 36, 6-13. [CrossRef]

14. Dallas, D.C.; Guerrero, A.; Khaldi, N.; Borghese, R.; Bhandari, A.; Underwood, M.A.; Lebrilla, C.B.; German, J.B.; Barile, D. A Peptidomic Analysis of Human Milk Digestion in the Infant Stomach Reveals Protein-Specific Degradation Patterns. J. Nutr. 2014, 144, 815-820. [CrossRef]

15. Nielsen, S.D.; Beverly, R.L.; Underwood, M.A.; Dallas, D.C. Release of functional peptides from mother's milk and fortifier proteins in the premature infant stomach. PLoS ONE 2018, 13, e0208204. [CrossRef]

16. Beverly, R.L.; Woonnimani, P.; Scottoline, B.P.; Lueangsakulthai, J.; Dallas, D.C. Peptides from the Intestinal Tract of Breast Milk-Fed Infants Have Antimicrobial and Bifidogenic Activity. Int. J. Mol. Sci. 2021, 22, 2377. [CrossRef] [PubMed]

17. Di Francesco, L.; Di Girolamo, F.; Mennini, M.; Masotti, A.; Salvatori, G.; Rigon, G.; Signore, F.; Pietrantoni, E.; Scapaticci, M.; Lante, I.; et al. A MALDI-TOF MS approach for mammalian, human, and formula milks' profiling. Nutrients 2018, 10, 1238. [CrossRef] [PubMed]

18. Hammer, B.; Strickert, M.; Villmann, T. Supervised neural gas with general similarity measure. Neural Process. Lett. 2005, 21, 21-44. [CrossRef]

19. Holland, J.H. Adaptation in Natural and Artificial Systems; University of Michigan Press: Ann Arbor, MI, USA, 1975.

20. Ménard, O.; Bourlieu, C.; De Oliveira, S.C.; Dellarosa, N.; Laghi, L.; Carrière, F.; Capozzi, F.; Dupont, D.; Deglaire, A. A first step towards a consensus static in vitro model for simulating full-term infant digestion. Food Chem. 2018, 240, 338-345. [CrossRef]

21. Brodkorb, A.; Egger, L.; Alminger, M.; Alvito, P.; Assunção, R.; Ballance, S.; Bohn, T.; Bourlieu-Lacanal, C.; Boutrou, R.; Carrière, F.; et al. INFOGEST static in vitro simulation of gastrointestinal food digestion. Nat. Protoc. 2019, 14, 991-1014. [CrossRef] [PubMed]

22. Miralles, B.; Sanchón, J.; Sánchez-Rivera, L.; Martínez-Maqueda, D.; Le Gouar, Y.; Dupont, D.; Amigo, L.; Recio, I. Digestion of micellar casein in duodenum cannulated pigs. Correlation between in vitro simulated gastric digestion and in vivo data. Food Chem. 2021, 343, 128424. [CrossRef] [PubMed]

23. Visser, S.; Slangen, C.J.; Rollema, H.S. Phenotyping of bovine milk proteins by reversed-phase high-performance liquid chromatography. J. Chromatogr. A 1991, 548, 361-370. [CrossRef]

24. Sánchez-Rivera, L.; Diezhandino, I.; Gómez-Ruiz, J.Á.; Fresno, J.M.; Miralles, B.; Recio, I. Peptidomic study of Spanish blue cheese (Valdeón) and changes after simulated gastrointestinal digestion. Electrophoresis 2014, 35, 1627-1636. [CrossRef]

25. Oliveros, J.C. Venny 2.1.0. Available online: https:/ / bioinfogp.cnb.csic.es/tools/venny/index.html (accessed on 25 March 2021).

26. Manguy, J.; Jehl, P.; Dillon, E.T.; Davey, N.E.; Shields, D.C.; Holton, T.A. Peptigram: A Web-Based Application for Peptidomics Data Visualization. J. Proteome Res. 2017, 16, 712-719. [CrossRef] [PubMed]

27. Caraux, G.; Pinloche, S. PermutMatrix: A graphical environment to arrange gene expression profiles in optimal linear order. Bioinformatics 2005, 21, 1280-1281. [CrossRef] [PubMed]

28. Jose'stam, J.; Sauer, P.J.; Boehm, G. Can we define an infant's need from the composition of human milk? Am. J. Clin. Nutr. 2013, 98, 521S-528S. [CrossRef]

29. Young, B.E.; Levek, C.; Reynolds, R.M.; Rudolph, M.C.; MacLean, P.; Hernandez, T.L.; Friedman, J.E.; Krebs, N.F. Bioactive components in human milk are differentially associated with rates of lean and fat mass deposition in infants of mothers with normal vs. elevated BMI. Pediatr. Obes. 2018, 13, 598-606. [CrossRef]

30. Kratzsch, J.; Bae, Y.J.; Kiess, W. Adipokines in human breast milk. Best Pract. Res. Clin. Endocrinol. Metab. 2018, 32, 27-38. [CrossRef]

31. Young, B.E.; Johnson, S.L.; Krebs, N.F. Biological determinants linking infant weight gain and child obesity: Current knowledge and future directions. Adv. Nutr. 2012, 3, 675-686. [CrossRef]

32. Lönnerdal, B. Bioactive Proteins in Human Milk: Mechanisms of Action. J. Pediatr. 2010, 156, S26-S30. [CrossRef]

33. Baba, T.; Downs, D.; Jackson, K.W.; Tang, J.; Wang, C.S. Structure of Human Milk Bile Salt Activated Lipase. Biochemistry 1991, 30, 500-510. [CrossRef]

34. de Oliveira, S.C.; Deglaire, A.; Ménard, O.; Bellanger, A.; Rousseau, F.; Henry, G.; Dirson, E.; Carrière, F.; Dupont, D.; Bourlieu, C. Holder pasteurization impacts the proteolysis, lipolysis and disintegration of human milk under in vitro dynamic term newborn digestion. Food Res. Int. 2016, 88, 263-275. [CrossRef]

35. Davidson, L.A.; Lonnerdal, B. Persistence of human milk proteins in the breast-fed infant. Acta Paediatr. Scand. 1987, 76, 733-740. [CrossRef] [PubMed]

36. Zhang, Q.; Cundiff, J.K.; Maria, S.D.; McMahon, R.J.; Wickham, M.S.J.; Faulks, R.M.; Van Tol, E.A.F. Differential digestion of human milk proteins in a simulated stomach model. J. Proteome Res. 2014, 13, 1055-1064. [CrossRef] [PubMed] 
37. Peterson, J.A.; Hamosh, M.; Scallan, C.D.; Ceriani, R.L.; Henderson, T.R.; Mehta, N.R.; Armand, M.; Hamosh, P. Milk fat globule glycoproteins in human milk and in gastric aspirates of mother's milk-fed preterm infants. Pediatr. Res. 1998, 44, 499-506. [CrossRef] [PubMed]

38. Beverly, R.L.; Underwood, M.A.; Dallas, D.C. Peptidomics Analysis of Milk Protein-Derived Peptides Released over Time in the Preterm Infant Stomach. J. Proteome Res. 2019, 18, 912-922. [CrossRef]

39. Wada, Y.; Phinney, B.S.; Weber, D.; Lönnerdal, B. In vivo digestomics of milk proteins in human milk and infant formula using a suckling rat pup model. Peptides 2017, 88, 18-31. [CrossRef] 